\title{
Grammar Teaching Materials: What Makes Them Interesting?
}

\author{
Maryam Sorohiti ${ }^{1, *}$ Eni Nur Aini ${ }^{2}$
}

\author{
${ }^{1}$ Universitas Muhammadiyah Yogyakarta \\ ${ }^{2}$ Universitas Muhammadiyah Yogyakarta \\ *Email: maryamsorohiti@umy.ac.id
}

\begin{abstract}
Teaching materials play an important role in English grammar mastery for students; however, there are possibilities that teaching materials might be perceived differently by either students or teachers. This study aimed to determine the EFL students' perception of interesting teaching materials used in learning grammar conducted at English Language Education Department of a private university in Yogyakarta. The respondents were six students who took Capita Selecta on Grammar classes. This descriptive-qualitative study employed a phenomenological approach to elaborate the findings through two stages of the study: the media of material delivery and what makes them interesting. The results showed that the respondents perceived four teaching material methods as interesting, i.e., audio-visual, audio, PowerPoint, and games. In addition, what made the materials interesting was the content, the technology used, and the delivery method. It is therefore hoped that grammar teachers are expected to be creative in developing grammar teaching materials as main supplements for the printed modules/books assigned to students to read since reading might bring about unfavourable effects such as boredom.
\end{abstract}

Keywords: Grammar, Teaching material, Interesting teaching materials, EFL students

\section{INTRODUCTION}

Language plays a very important role in our daily lives, because it is a way to communicate our ideas to others [1]. With language everyone can express feelings, wishes, opinions, and needs. Therefore, without language it will be difficult for everyone to understand the meaning of the words of others. English is currently very important to learn, because it is an international language that is generally used to communicate with people who come from abroad. In addition, English in Indonesia has also developed into a medium for self-image intellectually and socially. Many young people today use English in their daily activities, although there are still some of them who mix their mother tongue with English. This is added to the empirical reality which shows that most of the reference books used in higher education institutions in Indonesia are still written or published in foreign languages, especially English. However, in general the English skills possessed by students in Indonesia are inadequate.

Learning English grammar is a challenging thing for learners in Indonesia who do not make English a mandatory language in this country. This actually happens in other non-speaking English countries [2]. This is because English has a different grammar than these countries' language. In language teaching program, grammar is the necessary component as it is the fundamental and dominant position to help the learners reach certain language proficiency. As a crucial component in learning English, it is the basic skill for four other English proficiencies, i.e., listening, writing, speaking, and reading skills. Without knowing grammar, a language learner is barely able to acquire the other skills as aforementioned [3]. There are some factors to be believed as the trigger on why students become attracted to or avoiding the grammar lesson, including their interest on the methods and materials their teachers used in grammar classes [4].

Teaching material is a set of content in the curriculum that supports teachers in the teaching and learning process. [5] explained that teaching material is a key component in most language programs. It is the content of the curriculum in the form of subjects with topics accompanied by certain explanations [6]. In addition, it is equipped with things such as information, tools and texts that are to help teachers in delivering the material in the teaching and learning activities [7]. Based on the 
types of teaching materials, teachers may use the authentic and non-authentic/contrived ones [8]. Authentic materials are those not designed pedagogically but being used for learning. Some of examples are clippings, newspapers, movies, advertisements, or news. Authentic materials give learners into direct contact of reality level of English language because they are created by native English speakers [9]. On the contrary, nonauthentic materials are those prepared for pedagogical purpose such as books, handouts, worksheets, and modules [5]. Non-authentic materials are useful for teaching grammar in language learning process.

Teaching materials are an important part of the implementation of education in schools. Through teaching materials, the teacher will find it easier to carry out learning and students will be more assisted and easier to learn. Teaching materials can be made in various forms according to the needs and characteristics of the teaching materials to be presented. They are prepared with the hope of being useful for all parties with an interest in learning and expected to be used as a reference in developing students' skills in the future. Therefore, development of interesting teaching materials is the responsibility of the teacher.

Currently, we are living in the age of knowledge and technology, including the use of teaching materials. Technology makes it very possible for students, as learning subjects, to learn anything, anytime, and anywhere, whether they are deliberately designed or those who live to take advantage. The teacher's role has changed slightly. The teacher is not the only source of learning. Apart from themselves, teachers can develop and utilize various learning resources to facilitate the learning of their students. In the learning process, where students' learning is limited, tied, or controlled by curricular goals in the curriculum, the materials studied need to be selected and adapted to these goals. In other words, teaching materials must be created as interesting as possible by making use of technology.

It is at this time that the role of teachers and teaching materials becomes important and urgent to facilitate student learning both at school and when studying at home or elsewhere in order to achieve predetermined curricular goals. The teaching materials used by teachers and students in learning, if designed and developed carefully and according to the correct procedures referring to the principles of learning and the principles of effective message design for the student learning process, will be very effective in supporting or facilitating their learning process. With teaching materials students can repeat studying the material back at home. Developing teaching materials is one of the abilities that teachers must have [10]. This ability must be realized in an effort to provide various teaching materials needed by students in order to achieve the expected competencies. As a teacher, as well as a developer of teaching materials, the teacher is the person most responsible for managing the delivery of information and environmental arrangements in the process of mastering students' knowledge.

There have been several studies that put concern on the materials and the methods to deliver the materials [11]. However, most of these studies focused on quantitative study types and there have not, as far as we have searched on the topic, been any studies on grammar materials that students wanted which had been carried out with qualitative studies, especially with an emphasis on using the phenomenological approach. The current study using qualitative methods was aimed at exploring the students' perception embodied in the phenomena they revealed on the specific grammar materials and the use of appropriate learning aids in delivering the materials.

With their importance, students must be involved in determining which materials are the best to be used as teaching materials. This of course requires research to find out their perceptions of interesting and appropriate learning materials. For this reason, this study attempted to reveal the perceptions of students after they took and passed grammar classes about how the teaching material suited their wishes which they deemed appropriate and interesting.

\section{METHOD}

This qualitative study used a phenomenological approach to come across with the participants ideas of interesting and appropriate teaching materials. It included six students who had just taken Capita Selecta on Grammar class. This study used structured-interviews as the technique to collect the data. After the interviews, transcription was done to convert the audio into a text. After transcribed, the data was done member checking to obtain reliable data. In the proses of member checking, the participants checked the particular aspects of the interpretation of the data they provided as materials for the researchers to revise the transcript until all of the participants confirmed the transcript was the same as what they wanted to say. Coding was the next step to make the data easy to categorize for analysis.

This study underwent two stages, i.e., the first stage that concerned on the types (media) of material delivery and the second stage analyzing the reasons why the teaching materials could be interesting. The phenomenological approach would count the most in seeing deeper on the students' preference of interesting grammar teaching materials. Descriptively, each finding is then elaborated in the discussion to make each item clearer. 


\section{FINDINGS}

The findings are related to the teaching materials in grammar classes which attracted the students' interest.

\subsection{Media of Material Delivery}

\subsubsection{Audio-visual}

The participants mentioned that a video or a movie that contain entertainment for English learning was suitable teaching materials used to teach them in mastering English grammar.

"I love when the teacher uses expression in a movie to teach English grammar. For me, it is so obvious in terms of feeling on how I should use a specific English grammar or perhaps tenses in my daily conversation." (R.3)

"Audio-visual such as a fragment of a story in a specific background, for example, the difference between 'will' and 'be going to' feels so clear when we truly see 'the situation'. Consequently, we don't have to illustrate the grammar point in our mind based on the teacher's explanation, but we see it directly the use of correct grammar. That is what I feel when studying English with audio-visual" (R.5)

"The dialogue in a movie, for example, is so clear to illustrate the tenses. It is much different from what I have to go through when reading the textbook. Audio-visual indeed helps me understand English grammar more. In addition, by learning visually, I don't get bored easily." (R.6).

\subsubsection{Audio}

The respondents mentioned that audio materials are one of the interesting teaching materials when used properly. For example, when the teacher brought up a lesson using English songs, they felt that it was very valuable as they knew that songs were not always written with the correct grammar. This broadened their knowledge that some songs were meant to be composed in incorrect grammar to create the 'beauty rhyme' for the listeners.

"When the teacher explained the specific grammar using songs and she interestingly showed us which songs used the correct grammar and which songs used the incorrect one was epic. At that time, I could comprehend that, as a student majoring English like me, grammar could produce beauty when used properly based on the rhythm of a song." (R.1)

"I remember a song the teacher played with a lyric 'I don't care who you are, etcetera' and she explained it as a noun clause which is not written in a question form, indeed it made me understand the grammar. At first, when she used the textbook to give us explanation, I was still confused. However, after the song, it was clear to me.” (R.3)

"Listening using songs and after that my teacher explained the grammar was, in my opinion, the best part in teaching grammar. By enjoying the music, we know how to express our feeling, even with good grammar." (R.5)

\subsubsection{PowerPoint}

PowerPoint with the creative animation was attractive for students. All participants agreed that learning grammar using PowerPoint in the classroom was interesting. However, when the teacher could not make a good PowerPoint, the explanation fell into boredom for the students.

"Learning grammar was conducted by reading, discussing and doing the exercise using PowerPoint like you did in your classes was awesome. The layout including the amination you presented created a feeling to want more. Honestly, I was amazed with the teacher's skill in making PowerPoint when colors and shapes helped the students to wander more." (R.1).

"Learning using visual displays such as PowerPoints with animation is more fun than learning from printed books." (R.3)

"When the teacher used PowerPoint with the link was the amazing part of her teaching. She used example of grammar point in the PowerPoint by linking it to songs or movie clips; that was perfect. We didn't want to chat with friends but to focus on her explanations." (R.4)

\subsubsection{Games}

In this study, games using flash card or also using Kahoot! attracted the respondents as the fun atmosphere could make the students easier to understand any subject given.

"Teaching materials need to be more creative like using Kahoot! to deliver the material or replace the quiz to be more interesting. It becomes interesting and creative because it replaces paper-based examinations by utilizing classroom facilities" (R.3)

"Learning grammar using Kahoot! is more challenging. Flash cards are too. The point is that grammar is a heavy subject. It can be lighter when the teacher knows how to conduct the class, for example, by giving the students the appropriate and fun games" (R.5).

"Games are important in learning grammar. Therefore, the teacher must compose the teaching materials as interesting as possible, such as using games, with Kahoot! for example." (R.6). 


\subsection{Reasons of Why the Material is Interesting}

\subsubsection{The Content}

The material contents are the first thing that attracted the respondents in this study to learn English grammar. When the contents seemed not too formal by giving too many theories and much explanation, the respondents perceived that it is easy to grasp the meaning of the teaching materials delivered.

"The content. When the teacher present the explanation without having too much explanation but us as the students that must practice the theory in real sentences, it makes us valuable. Yes, it is so worth it." (R.2)

"We see that the explanation in the textbook is so simple to understand while asking the students to practice more. It is the translation that the teacher teach us that every single sentence can be felt the real meaning and usage with correct grammar. Yes, the content is the first thing that attracts me to learn more in the class." (R.6)

\subsubsection{Technology}

Technology indeed helps teachers develop teaching materials. PowerPoint with advanced technology, for example, can evoke different feelings inside the respondents compared to PowerPoint without any link to other technology forms.

"My teacher has brought us to the different level when she presented her PowerPoint. Her acquisition of technology makes us refresh our brain all the time. Previously, I thought that learning grammar could be very boring and tiring. But, when she involve technology, it becomes fun and interesting." (R.4)

"I love the way my teacher deliver her teaching materials when using technology. It creates different atmosphere while us practicing the correct grammar. Sometimes, I wonder why so many teachers still stick to the traditional way of material delivery when there is a tremendous progress in technology. She is a good example of using technology embedded into teachinglearning process." (R.5)

\subsubsection{The Material Delivery}

Students objected to the text-reading when studying. The class should be enlightening and not burdensome. This is the duty of each and every teacher to deliver the teaching materials in a fun and interesting way so that all students will get benefits from learning.

"I don't like when the teacher only reads the book and ask us to do the exercise. It is so boring and I really want the class session to end up quickly. However, when she delivers the material with the help, for example, technology and shes present clear and understandable examples, I become challenged. The class is no longer boring." (R.4)

"It is the teacher's performance that can change boredom to fun. Of course, the performance in this sense is the way she delivers the materials." (R.6)

\section{DISCUSSION}

Teaching materials can seem not to be interesting and boring [2], especially when students are required from book reading. Despite the fact that reading is one way of taking a way out to the answer to a question, it takes a full concentration to grasp the meaning from the text and it is a difficult thing to do for some types of students. It is therefore a challenge for all teachers to develop a teaching material that suits the learning goals as well as the interest of the learners.

Creative learning is something that must be considered by teachers and this type of learning requires interesting teaching materials [12]. In the current study, the respondents revealed at least four methods of teaching materials in grammar learning that were considered interesting, i.e., audio visual, audio, PowerPoint, and games. With the proper arrangement based on the content of the material, appearance, and presentation method, the grammar teaching materials provided by the four methods look more attractive to students.

\subsection{Media of Material Delivery}

\subsubsection{Audio Visual}

Audio-visual becomes the first perception of the interesting teaching materials in this study. According to [13], video can be effective for English learning, especially grammar. Meanwhile, [14] explained that video or movie can increase students' interest in learning as it can create an enjoyable feeling. The audio-visual used by teacher can make the students enthusiastic, because it provides a fun learning experience.

This perception is however in contrast with [11] that using media such as audio-visual cannot be assumed that students can learn languages more effectively. In addition, the material also should be selected and designed appropriately: teaching materials that work well in one class may not function well in other classes.

As the most widely taught international languages in many countries of the world, many citizens throughout the globe use English as a means of communication in important meetings at the international level. In Indonesia, English is the first foreign language studied as a compulsory subject from junior high school to college. One of the efforts to improve English language skills done by educational institutions is that English is introduced as early as possible, starting from elementary 
schools. In the world of higher education, students' English proficiency cannot be separated from the learning process provided by the teachers.

Teachers as facilitators try to provide the best teaching and learning process for their students [15]. One of the approaches given by the lecturer is to use learning media. Learning media is one component of learning that has an important role in the process of teaching and learning activities. Every teacher must take advantage of the media in every learning activity. Therefore, they need to learn how to determine the right media in order to streamline learning objectives.

Learning media has various types that can be used, one of which is audio-visual that can be accepted by the senses of sight and hearing. English is a subject that develops communication skills both orally and in writing, understanding and disclosing information. The process of teaching and learning activities by utilizing audio-visual media will be more effective, interactive and interesting. Teachers become more optimal in delivering material content and students will find it easier to understand. One example in teaching grammar, the teacher presents an English conversation video using a projector and loudspeaker and gives stresses on the grammar used by the speakers in the video. As a result, the process of teaching and learning English activities is no longer boring for the students. They become more motivated to learn English.

\subsubsection{Audio}

Audio listening materials when used appropriately can make student put so much attention on them. Audio can make students more concentrate on understanding material from the conversations in improving listening skill rather than using video which sometimes even makes students just enjoy the visual appearance [16]. According to [17], using an audio recording journal can improve students' listening skills and grammar.

Song is a very good 'tool' to help students learn English or, more specifically, songs are believed to be able to motivate students during learning English. It can also be said that songs are an important part of learning English because songs make students more sensitive to sounds, and learning language is nothing but learning various types of meaningful sounds. Songs can also make a class more interesting and lively. When students like the songs taught by the teacher, they will be happy and enthusiastic about doing it.

According to [18] there are many advantages to using songs as a learning resource. First, the song is a linguistic resource. In this case, the song becomes a medium for introducing new languages, as well as a medium for strengthening grammar and vocabulary. Songs also represent language that students have already recognized in a new and fun form. Songs also allow for natural and fun repetition of language. Songs can be used to develop all language skills in an integrative way, including improving students' pronunciation skills. Second, songs are an affective / psychological resource. Apart from being fun, songs are also able to motivate students and foster a positive attitude towards English. Songs are not something that scares or threatens students. Even songs can help increase students' self-confidence. As a proof that they have mastered something in English, students can proudly sing English songs in front of their parents. Third, songs are a cognitive resource. Songs help improve memory, concentration and coordination. Students become more sensitive to rhyme signs as a tool to interpret meaning. Forth, songs can be a culture resource and a social resource. [18] also revealed that, despite learning grammar, songs provide tremendous benefits for learning pronunciation. Some important features of pronunciation such as stress and rhythm and intonation can be trained naturally through songs.

Songs can be categorized into activity songs, animal songs, counting songs, food songs, learning songs, lullabies, patriotic songs, parody, sport songs, traditional songs, and so on. Consequently, we have to note that not all English songs can be used as a learning resource. Songs whose music is too dominant, for example, or songs that contain too much metaphorical language, slank language, are not good for learning. Teachers must choose songs that are simple and fit the learning needs (curriculum, for example). The choice of songs should also consider the lyrics that can be heard clearly, as well as correct pronunciation. As students will use the songs as a model, of course they have to find the best model. If the teacher is going to sing it, it must also be ensured that the teacher will provide a good model for the students. Regarding the 4 main skills that must be taught and must be mastered by students, i.e., listening, speaking, reading, and writing, grammar will always be present in each of them. Therefore, the choice of songs must be suitable with the delivery of good and correct grammar.

\subsubsection{PowerPoint}

Teachers' skills in making a very interesting PowerPoint containing teaching materials on grammar support the students' understanding on the materials. PowerPoint is more effective than textbook in encouraging students for learning [19]. Moreover, according to [20], PowerPoint can become the centre of students' attention although the content may not be interesting.

Effective teachers are able to master subject matter and strategies and skills in using teaching media. Today there are a lot of media that can be used by teachers or instructors in the learning process. Therefore, it is not only easier for the teacher to convey their knowledge but also useful for students to capture and understand lessons easily. PowerPoint is teaching media that can help 
teachers teach language skills, one of which is grammar. In this modern and technological era, teachers are required to be dynamic in relation to rapidly developing technological developments. If the teaching system used by teachers is still conventional, it is feared that students will find it difficult to develop and follow technological developments in society.

In the past, the conventional teaching system emphasized the activity of the teacher explaining in front of the class providing a blackboard or other supporting tools. Currently, teachers are facilitated by the presence of PowerPoint software which has an impact on students' understanding. In using PowerPoint media in the learning process, not all students and teachers know and understand the function of each menu in Microsoft PowerPoint. The teacher's role in being creative and innovating in composing material in an attractive manner is a major factor in addition to the other factors described above. Through the PowerPoint, students and teachers can combine with other methods to support language learning activities in class. The interest in using this media will continue to be of interest for the next years.

\subsubsection{Games}

The respondents in this study perceived that they enjoyed and felt enthusiastic in learning by using flashcard as teaching material in the classroom, especially when games were chosen as the theme of the class. This statement is supported by [21] that flashcard is able to contribute and support students in learning activity. Flashcard can help students memorize new vocabulary and this will later help the construction of grammar. In grammar classes, students are able to feel comfortable to remember new vocabulary through word card games when they have to make sentences with randomly selected words from their collections using the correct grammar [22]. Another game that can make student be interested in grammar is Kahoot!. It is an online platform which has been used recently in language learning as the creative tool to deliver the teaching materials or an assessment tool. Kahoot! is a free online application that teachers can access to teach all materials with various levels. [23] explained that assessment using Kahoot! can make students more interested and challenged. Therefore, Kahoot! is one of teaching material that teachers can use to teach grammar.

Many people think that English is a difficult and boring subject. To eliminate this perception, an English game should be created. Use of this game is intended to facilitate learning English. This game is also an appropriate learning medium to convey material in a fun and easy way. Technological developments make it easier to choose English learning games. English teachers can choose English learning games from the internet which are then applied in English teaching and learning activities.
There are many benefits of using English games in teaching and learning activities. Boredom and hardship are the main factors why many people are reluctant to learn English. Although this language is very familiar in the world, it still takes a long time to master it. To get rid of boredom of the English language, using English learning games is the best way that can be used. This method can be used in between teaching and learning activities where games are only a learning medium. However, teachers must understand not to apply too many games in English lessons. In addition, selection of games must be in accordance with the material described so that sustainability is created.

English games are also very useful to increase enthusiasm in English learning activities. This is because there are lots of communicative and collaborative games that can attract student involvement in the learning process. This English learning game can also increase student participation to be more active in teaching and learning activities. The most important thing is to choose the type of English learning games that suit the material and the character of the students themselves. If teachers are still unsure about using games in class or to teach children, they can practice them right away. They can try to observe the difference between learning English using games and not. In this time, games may also eliminate the perception that English is difficult. As English games are a technique that is widely used to teach English, there are many reasons why using games in learning English in the classroom, one of which is to bring joy to learning. For English teachers, the purpose of giving English lessons is so that the students can use the language. By using English games, students will unconsciously participate in using English and also directly stimulate students' interest in learning English.

The use of games in learning English, of course, must be carefully prepared by the teachers. Teachers must be able to focus the game's function in learning English, whether to attract students to learn, whether to provide fun exercises or to reinforce the material that has been taught. Some games require some material and equipment such as cards, pictures, pencils, paper, etc. which of course must be prepared in advance. In addition, the most important preparation is, of course, the teacher him/herself; the teacher must understand very well about the games to be applied.

\subsection{What Makes Them Interesting}

Although there are three items in this section of finding in this study, technology will become our centre of attention since the content and delivery method follow after the use of technology in teaching materials. [24] said that technology is somewhat a must in educational world. Technology is an effective and efficient medium in the teaching and learning process. As a learning medium, technology is associated with various activities 
that are used to access, collect, manipulate, and present or communicate information.

The technology referred to includes equipment (such as computers, laptops, and other devices), software applications and circuits (for example internet, Wi-Fi, local network infrastructure, and others.

The use of technology as a learning medium will clearly make the teaching and learning process effective and efficient because it can make it easier for a teacher to get or convey information (messages or content, material) lessons, can help increase student understanding, present data/information more interesting or reliable, facilitate the interpretation of data, and obtain information. Therefore, in this case, it can be said that technology as a medium plays an important role as an effective and efficient tool in the teaching and learning process. Learning activities are the most basic activities in the whole educational process. This means that educational attainment depends a lot on how the teaching and learning process is designed and carried out professionally. As today, using technology, especially laptops and the internet, is very helpful in teaching and learning activities.

In an effort to improve the quality of education, one of them is utilizing technology in the teaching and learning process which is oriented towards the interests of students and facilitates the need for cognitive, effective and psychomotor development. Technology is a system that can facilitate educators and students to learn more widely and also varied. The materials they can learn are also more varied, not only in the form of word presentation, but can be richer with text, visual, audio, film, and animation variations as illustrated in this current study.

The content of teaching materials along with the method on how the content is delivered may be dependent upon technology to make the materials interesting. The performance by creating, using and managing appropriate technological processes and resources is pivotal in delivering such interesting teaching materials [25]. The PowerPoint things mentioned in this study has demonstrated that effective technology can bring joys to the respondents to study. This is in line with a study by [24] that PowerPoint teaching delivery will be more enjoyable when technology is used appropriately. It will help in best utilizing the lecture time, limit disruption by students, provide outstanding methods for presenting the lecture materials, and enhance the concentration and engagement of the students.

This current study, using a phenomenological approach, has succeeded in revealing several inputs to teaching English, especially grammar. This can be seen from the phenomena expressed by respondents as consumers of this grammar learning. This qualitative research also touches their desires more deeply because they reveal things that suit their wishes without being guided by 'yes or no questions' as in quantitative studies. This suggests that, because language is always associated with feeling, qualitative research should be a counterweight to quantitative research.

\section{CONCLUSION}

This study concludes that grammar teaching can bring unfavourable impacts when it is conveyed in nonconducive situations. However, when grammar teachers follow technological developments, especially in terms of learning media, which are adapted to learning materials, learners can select which media is most suitable for them. This can be explored by knowing their opinion as much as possible about their comfort when learning grammar materials using the media/technology. In this study, PowerPoint linked to video and audio can give a deep impression on the respondents' feelings. Therefore, they revealed that this learning method with media was very suitable for them and helped them understand the materials given which were suitable for the real situation in the native speaker background seen in the video.

The phenomenological approach used in this study is very helpful for directing the analysis of the phenomena that occur in grammar learning, especially learning that includes media as a tool to convey learning materials. Studies on grammar materials can be recommended by using this approach to get positive and negative phenomena from the learners to improve the grammar learning method itself.

\section{REFERENCES}

[1] B. Stahl, B. Mohr, F. R. Dreyer, G. Lucchese, and F. Pulvermüller, "Using language for social interaction: communication mechanisms promote recovery from chronic non-fluent aphasia," Cortex, vol. 85, pp. 90-99, 2016.

[2] Z. Akbari, "Current challenges in teaching/learning English for EFL learners: The case of junior high school and high school," Procedia-Social and Behavioral Sciences, vol. 199, pp. 394-401, 2015.

[3] A. Anugraheni, Nurah Setya, "A sudy on students' grammatical errors in writing invitation cards at eight graders of SMP Negeri 2 Purwokerto in Academic year 2015/2016," Universitas Muhammadiyah Purwokerto, 2016.

[4] O. Tabatabaei and A. Molavi, "Demotivating Factors Affecting EFL Learning of Iranian Seminary Students," International Education Studies, vol. 5, pp. 181-190, 2012. 
[5] J. C. Richards, Curriculum development in language teaching: Ernst Klett Sprachen, 2001.

[6] M. Ruhimat, E. Ningrum, and B. Wijayanto, "The Implementation of Problem Based Learning toward Students' Reasoning Ability and Geography Learning Motivation," in IOP Conference Series: Earth and Environmental Science, 2018, pp. 1755-1315.

[7] A. Majid, "Perencanaan Pembelajaran (Bandung: PT. Remaja Rosdakarya)," 2012.

[8] J. Beresova, "Authentic materials-enhancing language acquisition and cultural awareness," Procedia-Social and Behavioral Sciences, vol. 192, pp. 195-204, 2015.

[9] D. Heitler, "Teaching with authentic materials," Encuentro, vol. 6, p. 10, 2005.

[10] J. Masuram and P. N. Sripada, "Developing spoken fluency through task-based teaching," Procedia Computer Science, vol. 172, pp. 623630, 2020.

[11] G. Ilin, Ö. Kutlu, and A. Kutluay, "An action research: Using videos for teaching grammar in an ESP class," Procedia-Social and Behavioral Sciences, vol. 70, pp. 272-281, 2013.

[12] D. Davies, D. Jindal-Snape, C. Collier, R. Digby, P. Hay, and A. Howe, "Creative learning environments in education-A systematic literature review. ," Thinking Skills and Creativity, vol. 8, pp. 80-91, 2013.

[13] S. Sarker and J. A. Nicholson, "Exploring the myths about online education in information systems," Informing Science: International Journal of an Emerging Transdiscipline, vol. 8, pp. 55-73, 2005.

[14] R. Selvarajan and V. Thiyagarajan, "Role of Videos to Enhance Learning Skill in English Language Teaching," Language in India, vol. 18,2018

[15] P. Purnaningsih, "Strategi Pemanfaatan Media Audio Visual untuk Peningkatan Hasil Belajar Bahasa Inggris," Jurnal Informatika Universitas Pamulang, vol. 2, pp. 34-41, 2017.

[16] R. Rahmatian and N. Armiun, "The effectiveness of audio and video documents in developing listening comprehension skill in a foreign language," International Journal of English Linguistics, vol. 1, p. 115, 2011.

[17] M. Rashtchi, M. Nourozi Khiabani, and N. Roumiani, "The effect of listening to self audiotaped journals on Iranian EFL learners $\Gamma$ grammar knowledge," Advances in Asian Social Science (AASS), vol. 4, 2012.
[18] J. Brewster, G. Ellis, and D. Girard, "The Primary English Teachers's Guide," ed: England: Penguin English, 2002.

[19] G. Corbeil, "Can PowerPoint presentations effectively replace textbooks and blackboards for teaching grammar? Do students find them an effective learning tool?," CALICO journal, pp. 631-656, 2007.

[20] A. R. Moghadam and H. Talafian, "Power point presentation and Iranian High School EFL learners' grammatical knowledge and interest," ed: University Sabzevar Iran: Iran, 2015.

[21] K. J. Grillo and L. A. Dieker, "A new twist on vocabulary instruction for students with learning disabilities in biology," The american biology Teacher, vol. 75, pp. 264-267, 2013.

[22] J. Aliponga and C. C. Johnston, "Benefits of Using Vocabulary Flash Cards in an EFL Classroom," 2013.

[23] N. N. Omar, "The effectiveness of Kahoot application towards students' good feedback practice," PEOPLE: International Journal of Social Sciences, vol. 3, 2017.

[24] J. AlAmmary, "Educational technology: A way to enhance student achievement at the University of Bahrain," Procedia-Social and Behavioral Sciences, vol. 55, pp. 248-257, 2012.

[25] R. C. Richey, "Reflections on the 2008 AECT Definitions of the Field," 2008. 